\title{
The Contribution and Reuse of LTER Data in the Provenance Aware Synthesis Tracking Architecture (PASTA) Data Repository
}

\author{
Mark Servilla, James Brunt, Duane Costa, Jeanine McGann, and Robert Waide \\ University of New Mexico, Albuquerque, NM 87131
}

\begin{abstract}
Sites in the Long Term Ecological Research (LTER) Network have now contributed greater than 5,000 data packages into the LTER Network Information System (NIS). This corpus of data and metadata allows us to analyze characteristics of data from the LTER program, including temporal coverage, data format, rate of submission, volume of data, and ecological characteristics of the data (e.g., ecosystems, processes, organisms). In addition, data/metadata congruence checks included in the Provenance Aware Synthesis Tracking Architecture (PASTA) underlying the NIS allow us to examine the quality of metadata submitted. Initial records of data use and citation provide the means to evaluate the efficacy of this repository in disseminating data throughout a broader community -89 citations of data packages found in 52 articles have been documented to date.
\end{abstract}

Keywords: LTER Network, Network Information System, Information Management, PASTA

\section{Introduction}

A milestone in informatics for the Long Term Ecological Research (LTER) Network [1, 2] occurred in January 2013 when the Network Information System, powered by the Provenance Aware Synthesis Tracking Architecture (PASTA)[3], went live. The NIS is the first Network-wide data repository that archives a significantly large corpus of complete LTER data and makes them accessible through a single web-interface to the broader ecological community and the general public. The NIS provides unique capabilities to LTER Network data management, including awareness of provenance metadata for tracking source and derived data, the evaluation of the data packages for structural and semantic quality as a pre-archival requirement before deposition, and the assignment of Digital Object Identifiers (DOIs) to all publicly accessible data.

We review the history and current state of the LTER NIS and analyze temporal coverage, data formats, rates of submission, volume of data, and ecological characteristics of LTER site contributed data to PASTA. Structural and semantic evaluation of science data and metadata allow us to examine the quality of data archived in the NIS. We also review the broader impacts of the NIS on ecological science and informatics by analyzing data downloads and citations to LTER data found in the scientific literature.

\section{Background}

Since its inception, the LTER Network has valued the contribution of information management to achieving its goal of creating well-designed and well-documented databases that are accessible to the broader scientific community and the public.
The early development of a community of information managers, the formulation of a Network-wide data access policy, and the decision to create a Network Information System were all steps towards achieving that goal. From the onset, the LTER Network understood the challenges inherent in harmonizing a diversity of data types, file formats, sampling strategies, and collection methods, especially across the locally-specific and context-dependent nature of site data. To address those challenges, the Network adopted a deliberate, open planning process that was both inclusive and long-term. This process encouraged joint planning by information managers and domain scientists and eventually engaged both groups in iterative cycles of software development and assessment.

The creation of a Cyberinfrastructure Strategic Plan [4] guided the development of the NIS. The strategic planning effort involved a diverse group of information technology (IT) specialists from science and technology centers, large IT development projects, and national observatory initiatives. This group conducted a series of meetings to identify and suggest solutions to challenges in information management associated with 1) multi-site experiments, 2) data integration, 3) modeling, and 4) system architecture and human resources. Recommendations from these meetings contributed to the design and development of a data warehouse framework, PASTA, which forms the centerpiece of the NIS. PASTA builds on existing LTER investments and experiences by integrating standard interfaces and approaches into its design. Innovations in PASTA's design include incorporation of data provenance, event signaling, and data quality checks as part of its service-oriented architecture.

Early planning for the NIS faced a critical decision on the degree of standardization that should be imposed on data. Because of the great diversity in data formats employed in the field 
of ecology, early planners focused on developing metadata standards that would facilitate the development of software tools to produce data in required formats. This approach was stimulated by discussions with domain scientists, who emphasized the frequent need to integrate and reorganize data to address evolving scientific questions.

A collaborative effort beginning in 1998 between LTER information management experts and partners at the National Center for Ecological Analysis and Synthesis (NCEAS), the San Diego Supercomputer Center (SDSC), and the University of Kansas Natural History Museum produced version 1.0 of the Ecological Metadata Language (EML) [5], an XML metadata standard that can document and describe in detail ecological data and their characteristics. Data that is described by EML facilitates quality checking, development of synthesized data products, and flexibility in data output via the PASTA Application Programming Interface (API). For example, LTER information managers have written programs to use the EML found in PASTA to generate data integration tools for the R, MatLab, SAS, and SPSS programming languages. Moreover, the development of EML allows the NIS to archive a broad variety of data types from typical tabular ecological data to remotely sensed imagery.

Assignment of a DOI to data in the NIS provides the means to track data re-use through citation in new publications. This feature was an important factor in engaging domain scientists in planning and development because it provides a means of assigning credit to data producers and thus addresses an important requirement of LTER scientists. Concerns about data piracy or misinterpretation still exist among ecologists in general $[6,7,8]$, but the widespread and continued contribution of data into the NIS from all active LTER sites has demonstrated that these concerns have largely been overcome within the LTER community.

\subsection{The Provenance Aware Synthesis Tracking Architecture (PASTA)}

PASTA is a software framework that implements a Service Oriented Architecture (SOA) design pattern [9] for the LTER NIS data repository. It consists of five tightly coupled services, 1) metadata and data management, 2) data discovery using the Apache Solr search platform, 3) data activity logging and audit, 4) user identification, and 5) data event notification, which form a unified repository application available through PASTA's API (Fig. 1).

The SOA design allows new or upgraded services to be added into the framework using a software neutral and low-impact approach. Internal communication between independent services, as well as client-to-PASTA communication via the API, is performed through the standard hypertext transport protocol (HTTP) and follows the tenets of RESTful web services [10]. All current software services are implemented using the Java programming language and take advantage of the Java Servlet framework for web application development. Although PASTA's services have been tested with various operating systems, including Microsoft Windows and Apple's OS X, they

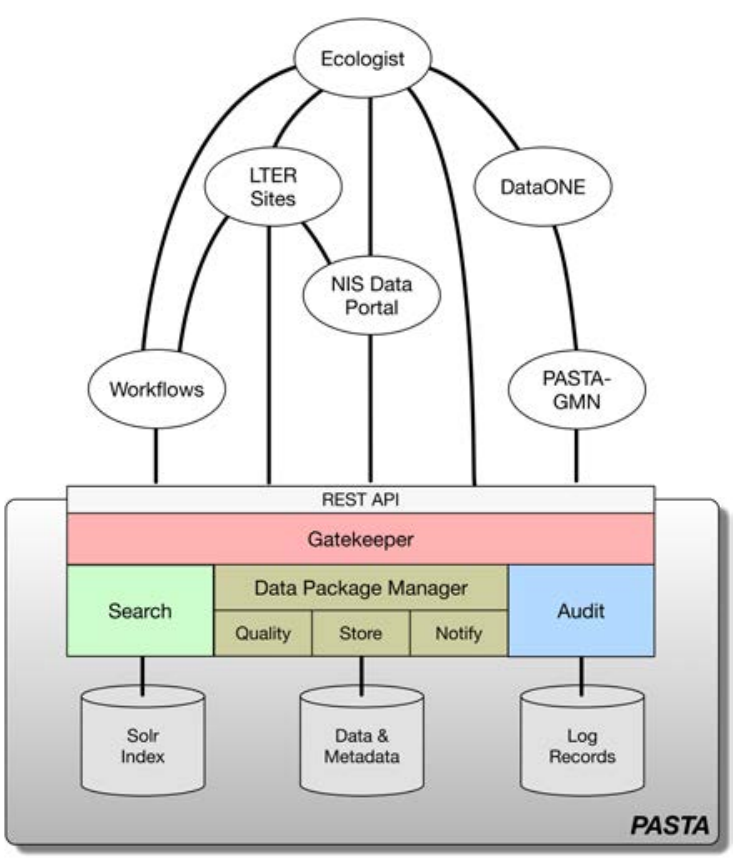

Figure 1: Conceptual diagram of the PASTA service stack and a generalized set of ecological data producers and consumers. PASTA service colors represent different virtual servers.

presently run on Ubuntu Linux in a virtualized computing environment that is managed by the LTER Network Office at the University of New Mexico.

As a data repository, PASTA requires that data and metadata are organized into a conceptual digital bundle called a "data package". Each data package consists of one or more data objects (i.e., the digital representation of tables, images, maps, or binary files) described by a single EML document.

Data packages in PASTA are represented by a 3-part unique identifier consisting of a contextual name (or domain scope), an accession number, and a version number called a "revision" (e.g., knb-lter-hbr.32.3). The contextual name generally denotes the LTER site where the data are collected, while the accession number uniquely identifies the data packages with the site context. The revision number marks time-ordered updates to the data package lineage. For example, a data package may contain bird population measurements at a particular location over time. New measurements may be added to the data package on a yearly basis, which would be indicated with new revision values (e.g., knb-lter-nin.10.1998, knb-lter-nin.10.1999, knb-lter-nin.10.2000). The data package identifier scheme used by PASTA follows the approach originally defined by Metacat [11], and for similar purposes.

An important feature of PASTA is the Event Notification service, which sends a web-service notification to any subscriber when an update to a specific data package occurs. The notification consists of an HTTP POST request to the registered URL of any "event listening" web-service whenever a data package is uploaded into PASTA. The subscription may filter on a specific data package revision, lineage, or even request a notification for all data packages uploaded from a specific LTER site. 
This feature may be used in the automatic execution of scientific workflows (see Case study below).

\section{Case study: An exemplar of an integrative data management solution using PASTA}

The Earth's environment is changing at local, regional, and global scales. Dramatic changes have occurred over the past century with important consequences for plant, animal, microbial, and human populations. Long-term data provide the only means to assess the rate and direction of change, to distinguish directional trends from short-term variability, and to forecast environmental conditions in the future. The EcoTrends Project promotes andenables the use and synthesis of long-term data to examine these trends in the Earth's ecosystems [12].

The EcoTrends project was a collaborative effort initiated by LTER scientists to make long-term, timeseries ecological data easy to access, analyze, and compare within and across sites. The authors developed a portal to provide data exploration, download, graphing and synthesis tools for a this large and diverse collection of standardized long-term ecological data from both LTER and non-LTER sites that extend to 2008.

The EcoTrends collection of data, although exceedingly valuable from an ecologist's perspective, has never been revised since they were published in 2008 . This is because considerable human involvement over many years was required to identify, prepare, and process raw heterogeneous data into that of a standard and comparable format. Our frustration with this labor intensive approach to providing useful ecological data gave us motivation and guidance in our development of PASTA.

As part of the initial design, PASTA implemented support for the execution of external workflows through its API and event notification service. Automated solutions to many routine data management tasks can be established by integrating external workflow processes to event subscriptions. We demonstrate an automated workflow for updating time-series data in PASTA using specialized workflow tasks for data analysis and processing initiated by linking their execution to an "Event Listener"(Fig. 2).

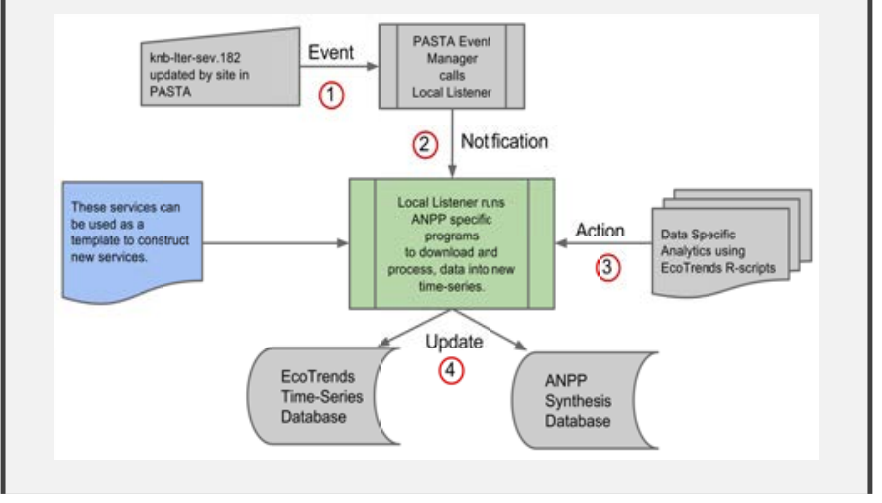

Figure 2: Example workflow process for exploiting the PASTA event notification system and API to update ANPP data. 1) The event the data package of interest is updated by site data manager, 2) Notification - the event notification system makes an HTTP "POST" request to the "Event Listener" URL, 3) Action - the listener executes a workflow that retrieves the updated biomass data from PASTA, analyzes the data, calculate annual ANPP data, and creates metadata for the new ANPP data package, 4) Update - the derived databases are updated using the new data.

Based on research by Knapp and Smith [13], the 2014 LTER Science Council ad-hoc science working group accumulated and analyzed annual Aboveground Net Primary Productivity (ANPP) data from all relevant LTER sites. We chose two sites that 1) had ANPP data in PASTA from the original EcoTrends project (archived in 2013), 2) had raw biomass data being actively collected at the same sites beyond 2008, the end of the EcoTrends project, and 3) had uploaded these new data to PASTA. These three conditions established a scenario to extend the original Ecotrends time-series data by using the new, raw data that were uploaded to PASTA.

For this example, we developed a workflow application (Fig. 2) with a local Event Listener that executes when a simulated data upload event notification occurred for a specific PASTA data package identifier (e.g., knb-lter-sev.182.1). The "Local Listener" was implemented in Python and triggers an R script that reads the raw ANPP data from PASTA and processes it into the EcoTrends standard format of ANPP.

This workflow, when executed, extends ANPP data from Sevilleta LTER site in central New Mexico for three spatially separated collection sites (Fig. 3). We executed a similar workflow for data from Jornada Basin LTER site. For these analyses, we used "R" scripts which were archived to support extending EcoTrends time-series data into the future. Subsequently, we updated the ANPP synthesis database using data for a common species (Bouteloua eriopoda) from both the Sevilleta LTER site and the Jornada Basin LTER site in south-central New Mexico(Fig. 4).

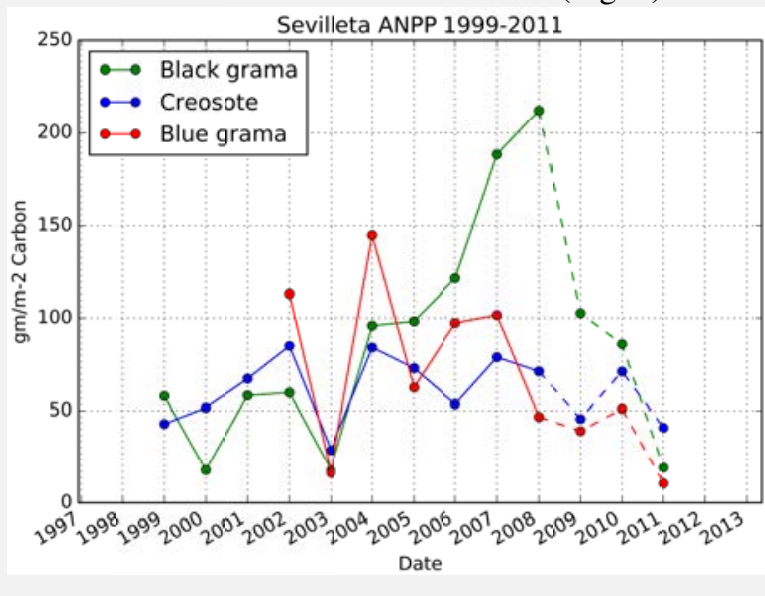


Figure 3: The Sevilleta LTER ANPP data extended from 1999 to 2011. Data from 1999 to 2008 from the EcoTrends project and from 2009 to 2011 Muldavin and Collins [14].

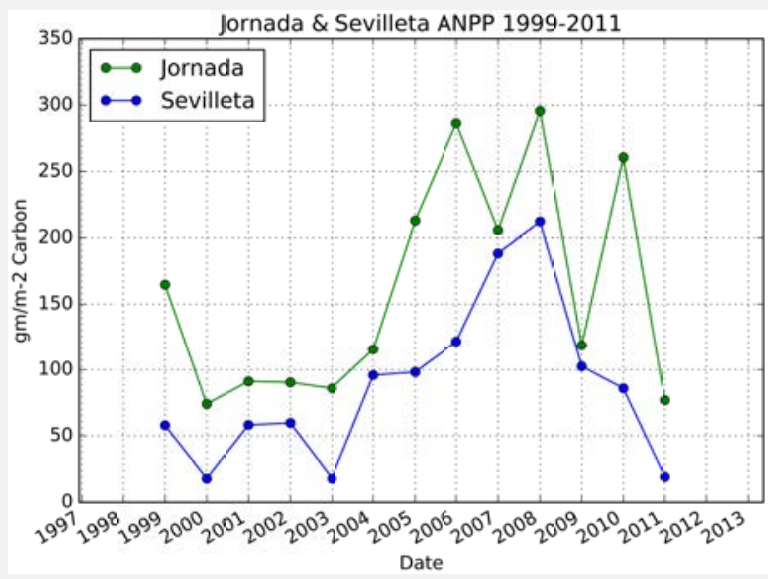

Figure 4: Compares time-series ANPP data for grasslands dominated by Bouteloua eriopoda between the Sevilleta and Jornada Basin LTER sites after the execution of the workflow.

We found that integrating workflows to use PASTA's data upload event notification service is not onerous and can easily be used to for time-sensitive data analysis, to create new integrative data packages, update datacentric web pages, send emails to interested persons, and can be extended for use by many applications that may benefit from automated execution. Secondly, we feel that when applied to a large series of cross-site data packages, this automated approach for workflow execution can simplify and accelerate data synthesis efforts. The creation of flexible event listener applications would add significantly to a data scientist's toolkit and make it easier to create continuously updated synthetic data packages [15]. Ultimately, the uses of the event notification service are limited only by the creativity of the user.

A unique aspect of PASTA is its quality analysis processing of submitted data packages. This analysis relies on a set of declarative rules that govern whether an attribute of the data package is within a range of values or meets a specific constraint. The quality analysis uses an open source Java library originally developed by the LTER and NCEAS called the "Data Manager Library", which is a component of the EML software distribution [16]. Quality rules evaluate the metadata for completeness (e.g., "does the metadata contain an author"), the data for availability (e.g., "does the data URL return values"), and the metadata and data for congruence (e.g., "does the metadata accurately describe the number of rows in a data table"). The type of data (e.g., tabular, raster, or vector) within the data package dictates what rules may be applied to the analysis. An "error" condition for any data package prevents the data package from being archived into PASTA. A report of the quality analysis is available to the user submitting the data package to assist in correcting any errors or warnings; successful uploads also archive the quality report, along with the data package, for re- view by the end user of the product. To date, LTER information managers have proposed 91 potential rules of which 32 have been implemented and are operational within PASTA.

The LTER NIS Data Portal website provides a fully featured user interface to PASTA, which supports data package uploads for data producers, as well as search and download capabilities for data consumers. The Data Portal also serves as a reference implementation of the PASTA API.

PASTA was released in January 2013 as the core infrastructure and data repository of the LTER NIS. PASTA also provides gateway services to the DataONE federation of science data repositories [17] as the primary LTER Member Node. It uses the DataONE Generic Member Node customized for PASTA (PASTA-GMN) to synchronize with the federation's Coordinating Node infrastructure.

\section{Methodology}

In this paper, we provide analyses of the characteristics of LTER site-contributed data packages in PASTA, we examine data package re-use through downloads, and we track data packages used in subsequent research through their PASTAassigned DOIs cited in peer-reviewed literature.

\subsection{Analysis of Data Package Contribution to PASTA}

As of October 2015, PASTA contained nearly 5,100 data packages that were contributed by 27 current and past LTER sites. In addition, PASTA contains about 36,000 derived timeseries (EcoTrends) and remote sensing (USGS Landsat) data packages contributed by the LTER Network Office at the University of New Mexico (the Ecotrends and Landsat data are not part of this analysis). A digital record for each data package, including revisions, is entered into a local PostgreSQL database and is used for resource management by PASTA. Information saved in the record includes the type of object (i.e., data, metadata, or quality analysis report), its permanent identifier (as composed of its namespace, accession number, and revision), and insertion date. We analyze data packages contributed by LTER sites from 1 January 2013 to 31 October 2015 for rates of insertion, the number and frequency of revisions, the number of data objects within a data package, and the volume (as reported in bytes from the Linux file system) of archived data objects.

In addition, we parse and analyze components of the science metadata found in EML documents for each site data package. These components are primarily the data format, keywords, and temporal coverage that describe the data package. The data format field in the EML consists of a natural language description of the type of data being described and are not bound by a controlled vocabulary. The keyword field may also contain natural language terms that may or may not adhere to a particular vocabulary or thesaurus. Elements of temporal coverage include only those fields that include both beginning and ending dates.

Examination of keywords associated with each data package by the data provider allowed us to describe the contents of the PASTA repository by scientific topic. We used three broad topics: 1) ecosystems, 2) organisms, and 3) ecological processes, 
to classify data in the PASTA repository using the Advanced Search feature of the LTER NIS Data Portal. We searched the keyword field of EML documents for each data object for terms associated with these three topics in the LTER Controlled Vocabulary. The Advanced Search feature allows for searches of specific terms as well as their synonyms in the Controlled Vocabulary. In a few cases, related keywords (e.g., herbivory/grazing/browsing, grasslands/meadows, and lakes/ponds) returned equivalent numbers of results that were summed under the first term. Other components of the science metadata vary considerably in composition and would warrant a more detailed analysis of only the science metadata, which is beyond the scope of this paper.

Finally, we look at the quality analysis reports for all site data packages that were successfully archived into PASTA. This analysis looks only at the number of warnings found in the quality analysis reports over time, as data packages that were found to contain errors during quality analysis are not stored in PASTA.

\subsection{Data Package Reuse and Citation}

We use two metrics to gauge "re-use": we analyze the "object request" information logged by PASTA to see how often data objects are downloaded through the PASTA API; second, we review the scientific literature for citations that reference the Digital Object Identifier (DOI) assigned to each PASTA data package. Determining the extent of "re-use" based on downloads alone is not tractable since information necessary to categorize "who" performed a download is not recorded. As such, data download analysis only provides an overview of outbound transfer events from PASTA. The citation of data in literature is only beginning to gain a toehold as an usable practice by ecologists. For this reason, we present our analysis of PASTA data package citation alongside a more traditional, but somewhat limited, analysis of data downloads.

Download requests, including those for data objects, metadata, quality reports, and other related content, are logged and maintained in a relational database by PASTA. This information contains an identifier for the requested content, the date and time of the request, and user information (only if the user had self-identified through a PASTA "login" process). For this paper, we analyze for frequency and patterns of daily download requests for data contributed by LTER sites from January 2013 through October 2015.

To track the usage of LTER data packages in journal articles since PASTA was integrated into the LTER NIS in 2013, we searched citations using the PASTA DOI shoulder “10.6073/pasta" in Thomson Reuters' Web of Science, Google, and Google Scholar. When an article contained a PASTA DOI in its references, acknowledgments, or article text, we considered it to have a PASTA citation and its reference information was downloaded. We also cross-referenced all DOI links to PASTA by author/owner to examine whether or not an article author was citing their own data package or if a third party was referencing an "up-stream" data package. If an article referenced more than one PASTA data package, all were noted as

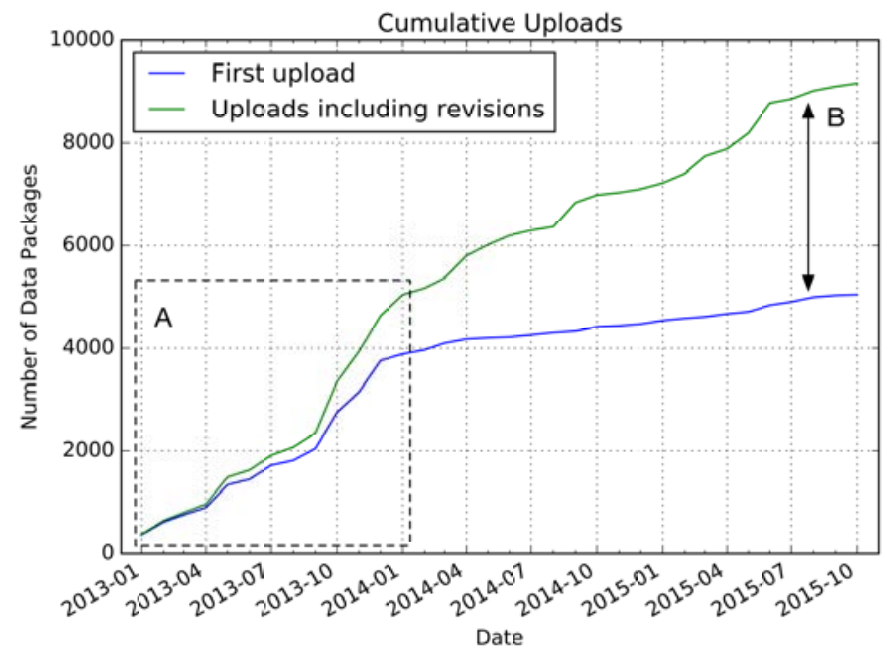

Figure 5: Cumulative uploads of LTER data packages into PASTA over time. Blue line indicates the cumulative number of new data packages uploaded. Green line indicates the cumulative number of new and revised data packages uploaded. Box "A" illustrates increasing the period of fastest growth. Line "B" illustrates the increasing difference between new to revised data packages beginning in October 2013.

unique citations. We captured the names of all author(s), journal names, the date of publication, and other relevant information for each article that referenced a PASTA data package, and we created a cumulative chart of citations to track them over time.

\section{Results and Discussion}

\subsection{Characteristics of Data Package Uploads}

In the period from January 2013 to 31 October 2015, LTER sites contributed 5,047 data packages to PASTA, with an additional 4,098 data package revisions, for a total number of 9,175 unique data packages. Between January 2013 and December 2013, the rate of data package contribution was nearly 6 times greater than in the period between December 2013 and October 2015 (Fig. 5). Beginning in January 2014, revisions to previously uploaded packages outnumbered new data packages.

The greatest contribution of "first-time" data packages occurred within the first 12 months after PASTA's release, with a considerable surge in Fall 2013 (Fig. 6. The rate at which new data packages were uploaded declined after January 2014. The number of data package revisions increased beginning in October 2013, and continued in four major pulses during 20142015(Fig. 6).

Upload characteristics of individual sites reflect three distinct strategies: early adopters began uploading data in January 2013, immediately after PASTA's release, while intermediate adopters delayed uploading data for between 1 to 7 months. Four sites were considered late adopters and did not upload data to PASTA until after January 2014, with the latest firstupload for a site occurring in June 2015. Anecdotal accounts of "late adopter" delays include site policy decisions that did not support anonymous access for data to insufficient resources for ensuring that data packages include unfettered access to data. 


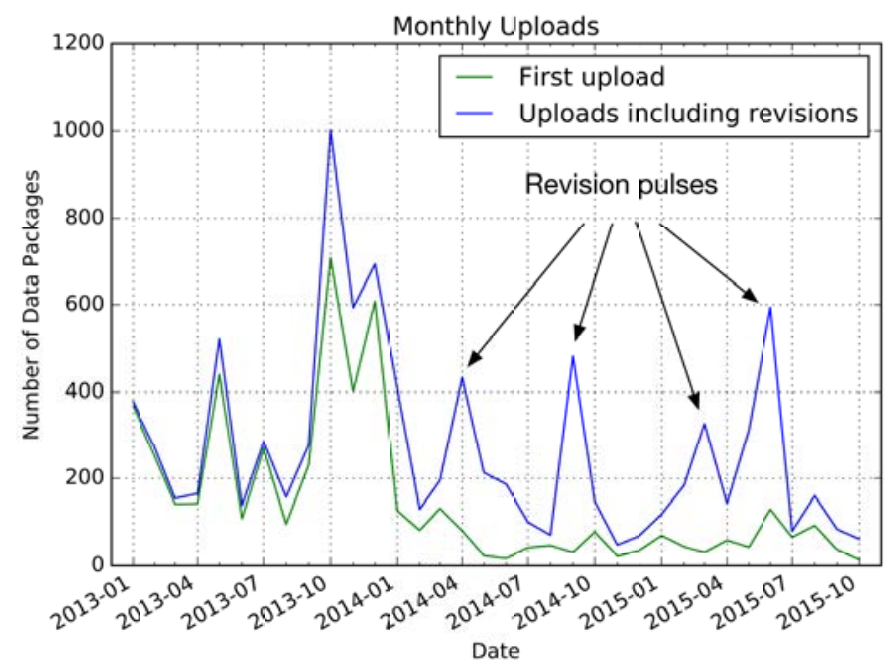

Figure 6: Monthly uploads of LTER data packages into PASTA over time. The green line indicates upload rate of the first data package of a series. Blue line indicates upload rate of all data packages, including revisions. Revision pulses are periods where data package revisions greatly outnumbered the upload of new first-time data packages.

The analysis of first-time contributions to the PASTA data repository shows that roughly three-fourths of the LTER Network research sites uploaded a majority of their available data to PASTA within the first year of operation. This initial phase, between January 2013 and January 2014, resulted in almost 4,000 data packages being added to PASTA (see box A of Fig. 5 ) in a relatively short period of time. We believe this high-rate of contribution can be attributed to a series of community activities that engaged both the LTER science and technical constituents in discussions about how to best manage their data holdings long before PASTA was designed and implemented.

Following this initial period, the addition of revised data packages became more prominent in PASTA as the contribution of first-time data packages slowed to a rate of approximately 600 per year as compared to 1,700 per year for new revisions (see spread denoted by line B in Fig. 5).

\subsection{Characteristics of Data Volume}

LTER sites contributed just over 250 Gigabytes (GB) of science data into PASTA during the period between January 2013 and October 2015 (Fig. 7). Data volume followed a consistent upward trajectory over this period consisting primarily of many, small-volume data objects, with $80 \%$ of data objects in PASTA being less than $1 \mathrm{MB}$ in volume. (Fig. 8).

There were, however, two significant upload events during this period that resulted in abrupt increases in cumulative volume: the first occurred during November and December 2013 when two large objects (files of $50 \mathrm{~GB}$ and $28 \mathrm{~GB}$, respectively) were added to PASTA (see A in Fig. 7); the second (and smaller of the two events) occurred in August 2015 with the addition of another two relatively large objects (7 GB and 13 GB files; see B in Fig. 7). Peaks in data volume are primarily attributed to single data objects, as opposed to surges in many small data objects. Interestingly, all four large objects were contributed from the same LTER site.

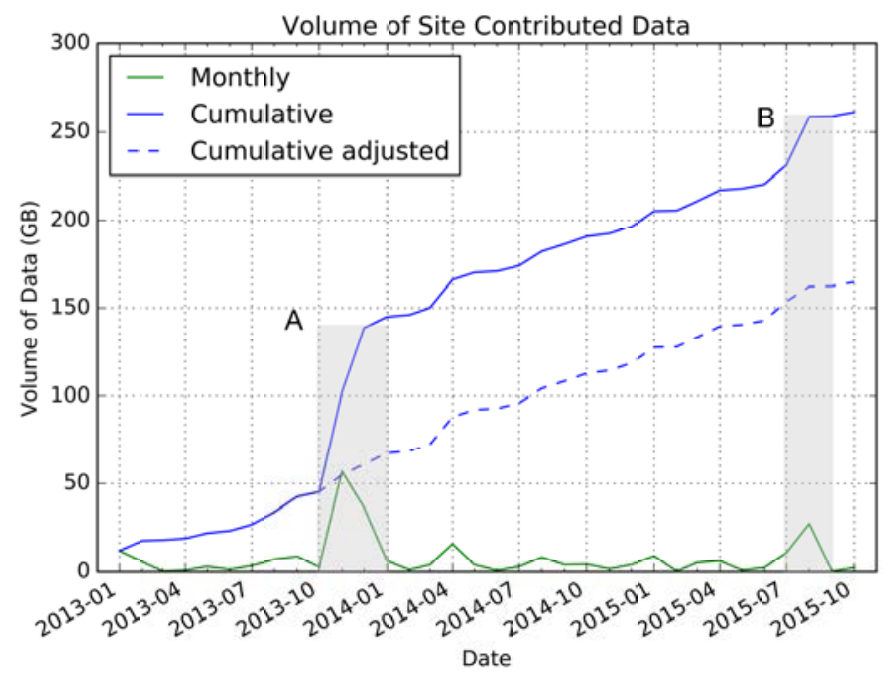

Figure 7: Volume (Gigabytes) of site contributed data over time as reported by the file system. The dashed line represents an adjusted cumulative volume if the four large objects were never added.

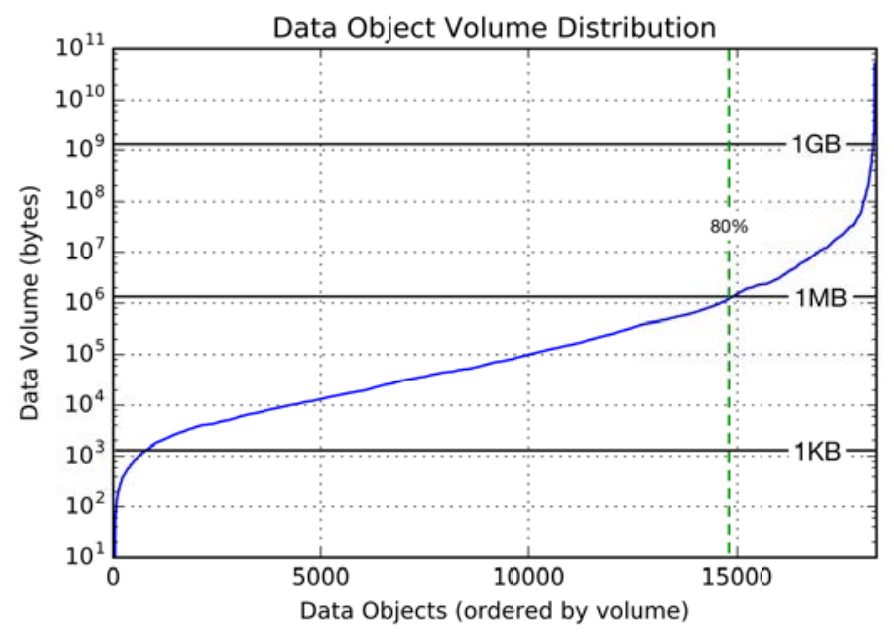

Figure 8: Volume distribution of all data files contributed to PASTA from January 2013 to October 2015 with thresholds marked for $1 \mathrm{~KB}, 1 \mathrm{MB}$, and $1 \mathrm{~GB}$.

The mean volume of data files in PASTA is just under 15 $\mathrm{MB}$, but this value is affected by the four very large data files described above. The mode, at $72 \mathrm{~KB}$, is closer to what can be expected for the volume of a data file found in PASTA.

\subsection{Characteristics of Data within a Data Package}

More than half $(56 \%)$ of all data packages uploaded to PASTA contain only a single data object(Fig. 9); nearly a third (29\%) have only two data objects. The number of data packages with greater than 3 data objects is less than $15 \%$, with the largest number of data objects in a single data package being 48. Our conjecture is that this is a result of the variation in information management practices between LTER sites. Most sites choose to describe one or two related science data objects within a single data package as opposed to many different nonrelated data objects, even if the data objects were the product of the same study. 


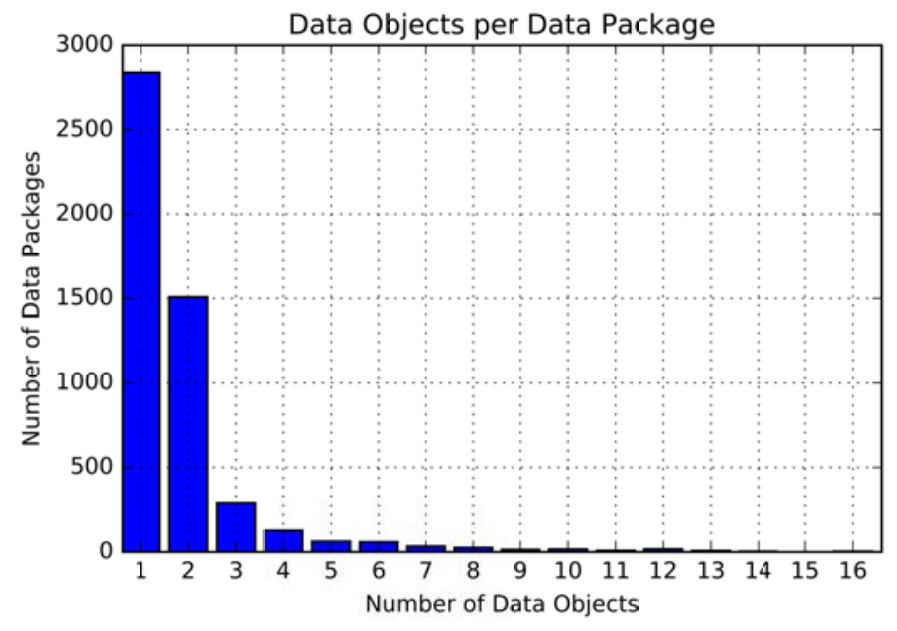

Figure 9: The number of data objects per data package in PASTA. Analysis is based on the most recent data packages in PASTA.

Data format descriptions provided by LTER sites in their EML science metadata varied considerably: there were 113 unique natural language descriptions of uploaded data object formats. We classified the broad group of data formats into one of following 6 base categories:

1. Tabular $-77.4 \%$ (e.g., csv, tsv, or application spreadsheet)

2. Spatial - $11.7 \%$ (e.g., ESRI Shapefile or other GIS format)

3. Archive $-3.8 \%$ (e.g., zip, tar, or other archive format consisting of multiple data types)

4. Raster $-3.7 \%$ (e.g., image format, including imagery in an archive format)

5. Document - $2.9 \%$ (e.g., text, PDF, MS-Word, or other nontabular data)

6. Other $-0.6 \%$ (including software code, audio, or nonindentified formats)

These results compare well with LTER's core data types and collection methodologies. We find no unusual data object formats within PASTA.

\subsection{Characteristics of Data Package Revisions}

A great majority $(96 \%)$ of data packages in PASTA have three or fewer revisions (Fig. 10). Almost half (46\%) of all data packages in PASTA have never been updated or modified since their initial upload as indicated by their single revision. The highest number of revisions for a data package in PASTA is 16 .

Most LTER sites revise their data continually on at least an annual basis, although some revisions take place at longer intervals, perhaps because of time constraints. However, seven distinct intervals where the number of revisions were significantly high (less than 1, 13, 21, 36/37, 42/43, 61/62, and 76 weeks; Fig. 11) suggest that some sites prepare and submit data revisions in a "batch". Those revisions that do occur within 1 week of the original data upload are likely due to errors or omissions found in the original data package. Peaks in data revisions beyond one week generally result from the activities of

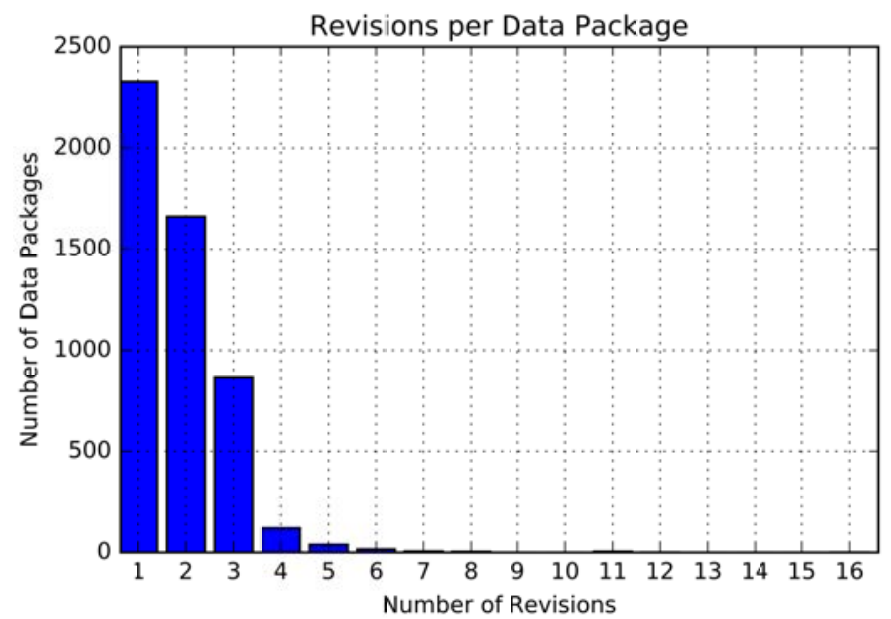

Figure 10: The number of revisions per data package for all data packages in PASTA. Each revision indicates the number of uploads for a specific data package lineage.

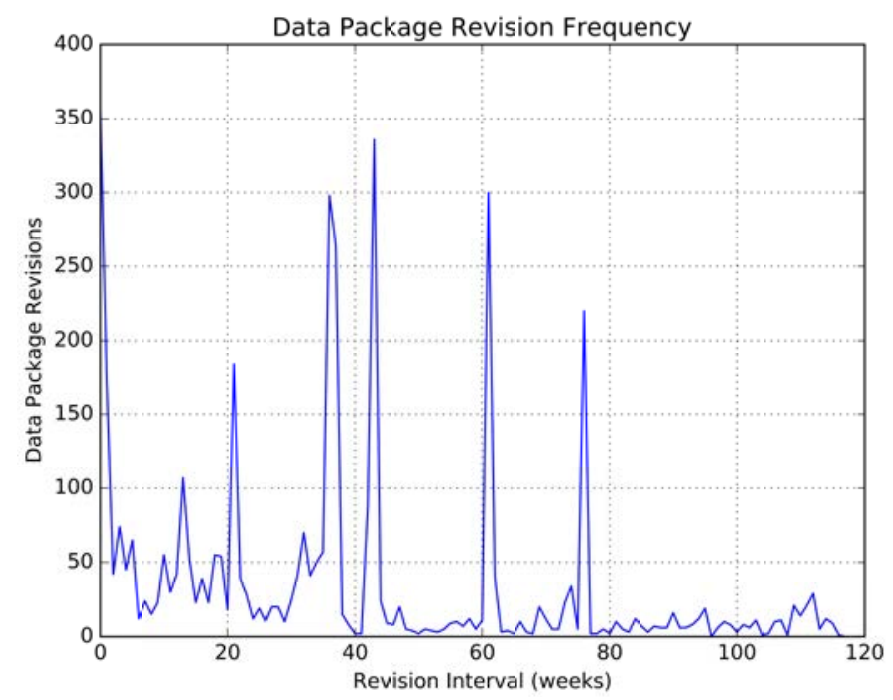

Figure 11: Frequency of data package revisions using a weekly interval period for data packages with 1 or more revisions (in-graph numbers indicate weekly interval for specified peak).

single sites. Continual and batch revision patterns may reflect differences in lengths of field seasons or other constraints that are specific to sites. Batch revisions may also explain the four pulses we see in uploads during Spring and Fall of 2014 and Spring and Summer of 2015 (Fig. 6).

\subsection{Characteristics of Data Package Temporal Duration}

Of the 5,047 data packages submitted to PASTA, 4,535 $(90 \%)$ include metadata containing a start and end date. We analyzed the time duration (Fig. 12) on a yearly scale and found $51 \%$ with a duration of 2 years or less $-10 \%$ of the data packages have a study duration of 25 years or greater. This large majority led us to re-analyze the data on a weekly scale out to a 5 year maximum (Fig. 12 Inset). In this case, we found a distinctive pattern that can be divided into two groups: (1) data packages with a study duration of 6 months or less, with a high 


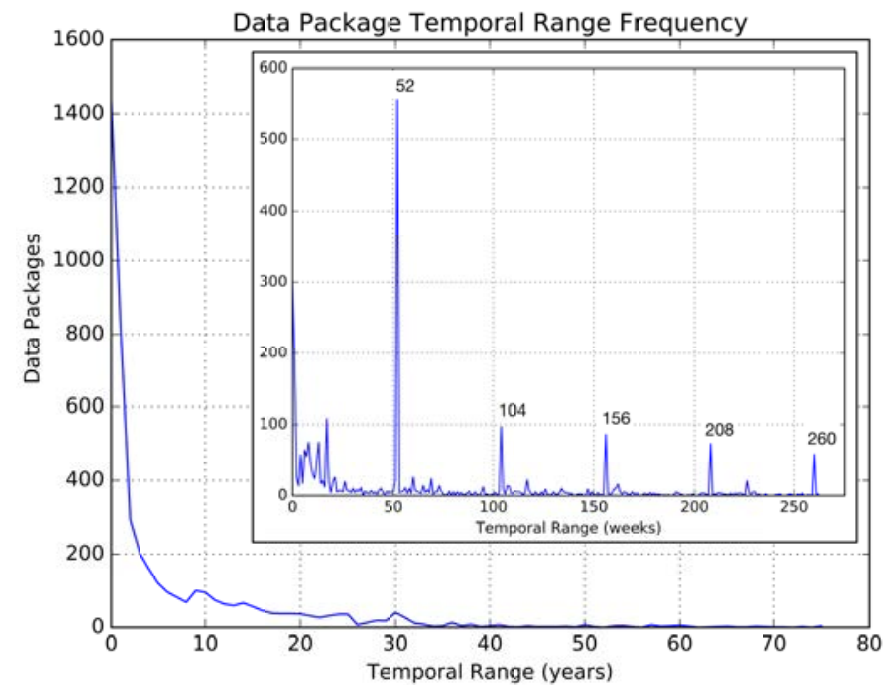

Figure 12: Interval of time during the scientific collection of data as denoted in the "temporal coverage" element of the Ecological Metadata Language document provided with each data package. Inset shows repetitive pattern of yearly collection data in units of weeks for 5 years.

concentration of these being less than one week and (2) those with a duration that are multiples of a year, of which a one-year duration is by far the most common.

Data packages that fall within the first group are likely shortterm efforts constrained to one-time studies or field-seasons of less than one year. Interpretation of those data packages with a duration that fall on yearly intervals, however, may be deceiving at first glance. These data packages may actually be the result of "splitting" long-term studies (e.g., 10 years) into smaller, annual data packages; this practice is common among some data managers who find it more efficient to document data in annual or smaller chunks for the purpose of archiving. This is in contrast to another common data management strategy called "lumping", which occurs when many years of data are aggregated over time and within a single data package. Both approaches are legitimate and accepted practices by LTER data managers. As such, the stated duration of a data package does not always reflect the true duration of the study.

\subsection{Ecological Characteristics of Data Packages}

Similar numbers of data packages were found for aquatic/marine $(2,014)$ and terrestrial $(1,914)$ ecosystems (Fig. 13A). River and stream ecosystems had the largest number of data packages, and lake/pond ecosystems had the third largest, which is unsurprising considering that all LTER sites have one or more of these aquatic features. Among terrestrial ecosystems, the largest number of data packages is associated with forest ecosystems. Plants (852) outstripped both animals (747) and microorganisms (175) in the number of data packages (Fig. 13-B). A surprisingly small number of data packages exist in PASTA for two important vertebrate groups, reptiles and amphibians. There is a strong focus on primary production as an important ecological process at all LTER sites as demonstrated by the large number of data packages in Figure 13-C.
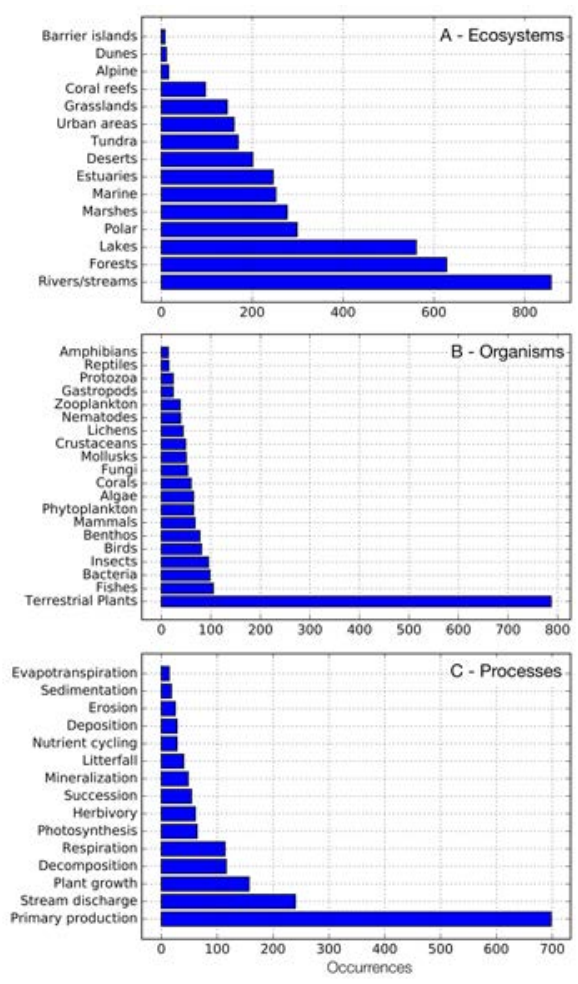

Figure 13: Numbers of data packages by topic area. Each topic is divided into sub-topics chosen from the LTER Controlled Vocabulary to represent ecosystems, organisms, and processes that are commonly studied in the LTER Network.

Our attempts to conduct more sophisticated keyword analyses were stymied by a lack of uniformity in the use of keywords across LTER sites. Despite considerable effort spent on the development of the community-based Controlled Vocabulary [18], even some relatively simple searches were difficult or impossible to perform. For example, analysis of the number of data packages associated with each of the five LTER core areas (e.g., primary production, populations, organic matter flux, inorganic matter cycling, and disturbance) was impossible because of differences among LTER sites in the keywords used to describe these core areas of research. Although the Controlled Vocabulary attempts to address this issue, only a few sites have implemented the relevant recommendations. Moreover, despite the efforts to limit keywords to terms in the Controlled Vocabulary, data currently in PASTA are described by over 6,000 unique keywords, 2,498 of which are used only once. Hopefully, continued efforts to implement the Controlled Vocabulary will lead to improved capabilities to mine LTER metadata.

\subsection{Characteristics of Data Package Quality Over Time}

PASTA's data and metadata quality analysis of submitted data packages indicates that LTER site information managers improve overall quality of data packages over time. Both the number of data package revisions with quality analysis "warnings" and the average number of "warnings" for each set of quality analyses of a data package decrease with newer versions(Fig. 14). This observation suggests that site information 


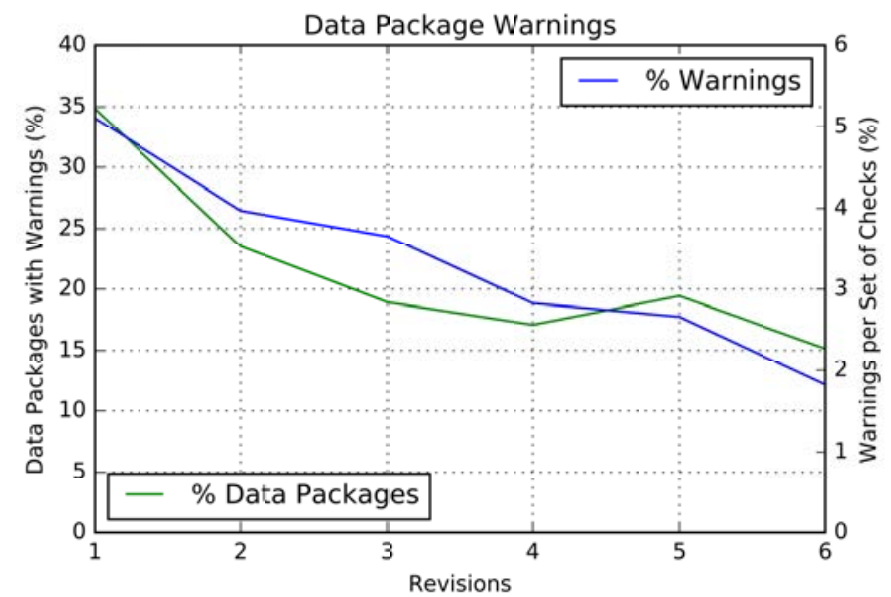

Figure 14: Change in the number of warnings in data package revisions over the total number of revisions for all data packages up to 6 revisions.

managers learn from previous mistakes and improve the quality of new revisions. We note that data beyond 6 revisions becomes suspect due to a diminishing sample size to analyze.

\subsection{Analysis of PASTA Data Package Re-use and Citation}

Perhaps the most effective measure of success for the PASTA data repository is the frequent and unfettered "re-use" of data stored in the repository. Both data download requests and the tracking of citations of PASTA data in published work are useful metrics to examine this.

\subsubsection{Data Downloads}

A total of 920,247 site data objects were downloaded from January 2013 through October 2015 (Fig. 15). Two distinct patterns are visible during this period: one of continuous downloads and another of "pulse" downloads. Continuous downloads averaged tens to hundreds per day, while "pulses" often exceeded 15,000 per day (with a maximum of nearly 35,000 in a single day). The number of continuous downloads gradually increased from less than 100 per day to an average of 350 per day. No other obvious trends were found associated with continuous downloads. Analysis of the "pulse" activity, however, revealed that downloads followed a regular pattern based on the alpha-numeric ordering of the data package identifier. This pattern suggests "pulse" downloads were the result of search engine "crawlers" methodically scanning the Data Portal website for linked content in PASTA. The frequency and duration of these events increased toward the end of 2014; we attribute this increase to the upload of a large number of remote sensing data packages (about 21,000) to PASTA in the same time period. We also found that the pattern of requests had become less ordered, which may represent a range of crawlers using different strategies to concurrently scan PASTA.

\subsubsection{Citation}

One supposition regarding the publication of data in repositories is that the data will be re-used and the original data cited, thus providing a benefit to the person publishing the data in the

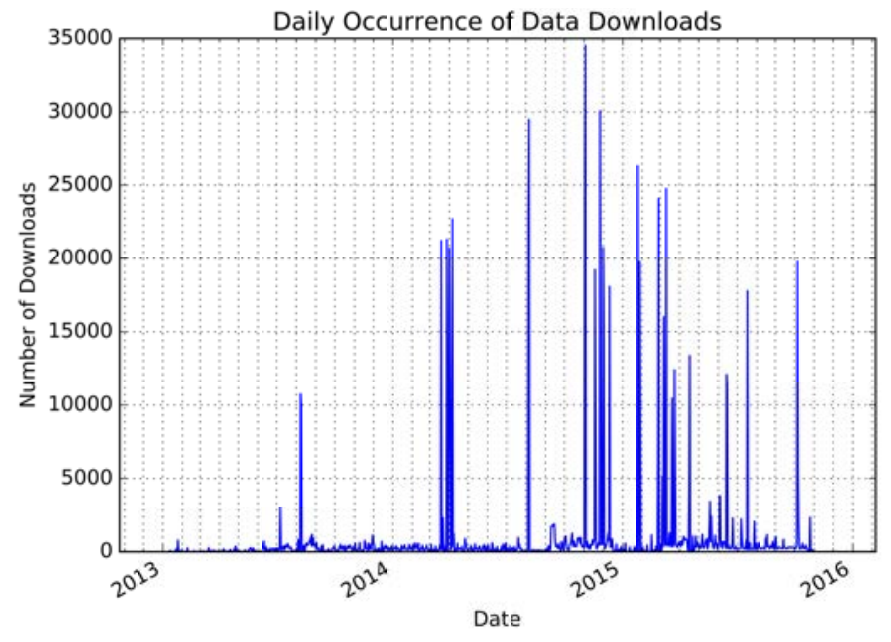

Figure 15: Daily occurrence of download requests for LTER site contributed data objects from PASTA.

form of academic recognition. Although this is one of the primary non-altruistic arguments for publishing data, the degree to which the supposition is true is seldom evaluated. Our search for citations that reference PASTA data packages in Thomson Reuters, Google, and Google Scholar demonstrate there exists an ever increasing use of LTER data since January 2013.

An initial search of Thomson Reuters' Web of Science site for terms including "LTER + articles + 2013, 2014, 2015" resulted in a list of many LTER articles, but none including DOIs that specifically referenced PASTA data packages. A further search specifically for citations using the 10.6073/pasta DOI "shoulder" resulted in a list of data packages as they exist in PASTA, but as before, no direct citations in articles. We did find that 254 of these data packages showed at least one 'usage', which Thomson Reuters defines as "a measure of the level of interest in a specific item on the Web of Science platform." This measurement only tracks "click-throughs" of links to the item as well as the saving of an item by a user in a bibliographic management tool.

We had greater success by searching for the DOI shoulder in Google and Google Scholar. Using this method, we were able to discover citations for 89 (82 unique) PASTA data packages in 52 articles (see Appendix A) published in 42 scientific journals. The search using Google Scholar was most successful; 45 articles citing PASTA data packages were found. A separate internet search using Google discovered 7 additional articles containing PASTA data package DOIs. We were, however, unable to determine whether the data packages were obtained from the LTER Data Portal or through some other mechanism, but the DOIs for the cited data packages were all assigned by PASTA.

Of the 89 data packages cited, 37 were by the person listed in the PASTA data package metadata as the owner, while 52 citations reflected re-use of the data by other individuals. The preponderance of data citation by others compared to self-citation suggests that 1) data publication can contribute to re-use, at least in this small sample and 2) LTER scientists have not yet developed the habit of citing their own data in their published 


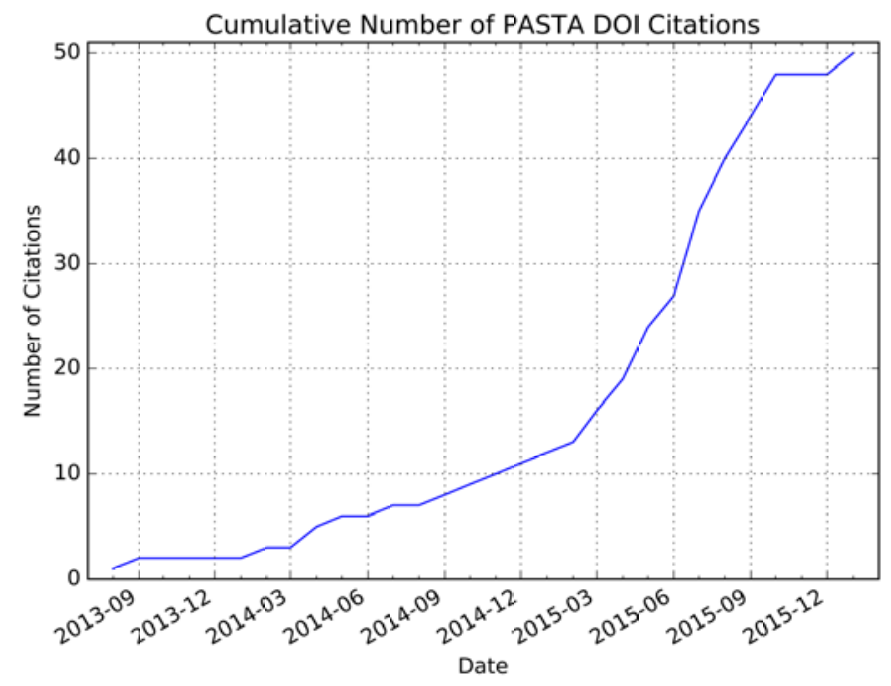

Figure 16: Cumulative count of publications citing PASTA data packages from August 2013 through the present. As PASTA data becomes more discoverable, citation levels increase.

papers. We found most references to PASTA data packages in the "Literature Cited" section of the articles (74), but some references occurred in the Acknowledgments section (13) or in the body of the paper (2). We note that references to PASTA data packages found in the "Literature Cited" section of an article are more likely to be discovered and identified by indexing services than by references in the "Acknowledgments" section or the text body of the paper. Scientific journals should address this point to authors in their instructions and editing practices in order to insure that data providers receive appropriate credit.

Because there is an inevitable lag between the publication of data and their subsequent re-use in scientific articles, we expected to see a gradual increase in citations of LTER data beginning shortly after the PASTA repository was released in January 2013. The first data citation we discovered was in August 2013 (Fig. 16), and citations accumulated steadily from that date forward for about 18 months. In February 2015, the rate of citations began to increase and continued to do so until the present. We were unable to determine if this gradually increasing rate of citations reflects an increased rate of discovery and re-use of PASTA data packages and whether the increase can be attributed to the existence of the LTER Data Portal or if it is simply an artifact of the lag time between data discovery and publication of articles re-using these data. As more examples of data re-use occur over time, we expect to be able to distinguish between these explanations.

Articles citing PASTA data packages appeared in a broad range of journals (Fig. 17; Appendix A), but a small sample size restricts our ability to discern patterns. The greatest number of data packages cited by a single article was 7 (Fig. 18). Thirteen of 52 articles $(25 \%)$ used more than one PASTA data package.

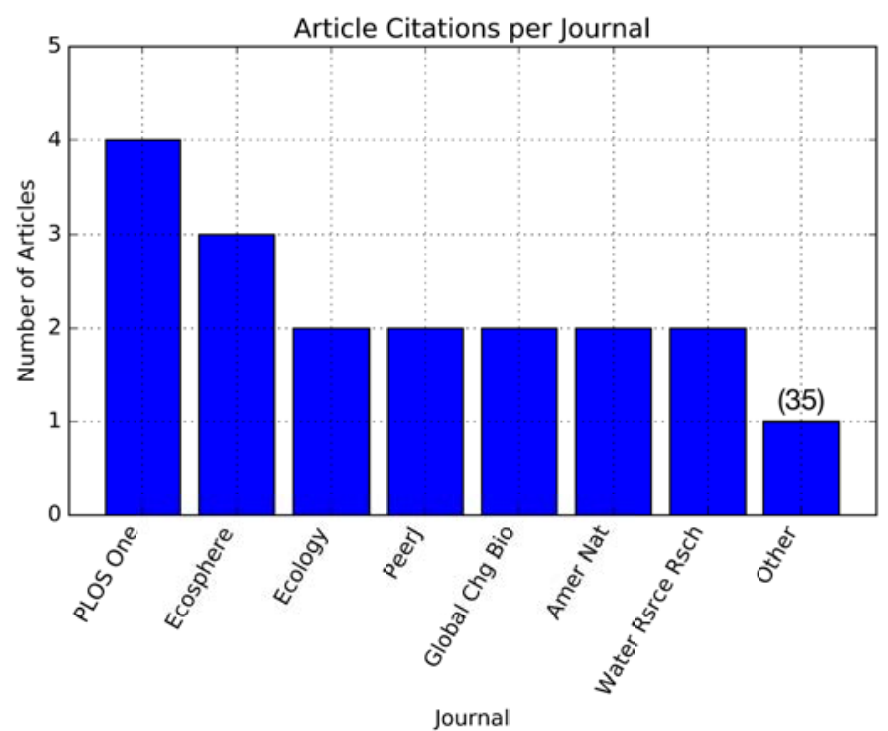

Figure 17: The journals where PASTA data have been most cited in articles. Seven journals contained two or more articles that cited PASTA data, 35 other journals had at least one. The 42 journals contained 52 PASTA-citing articles overall.

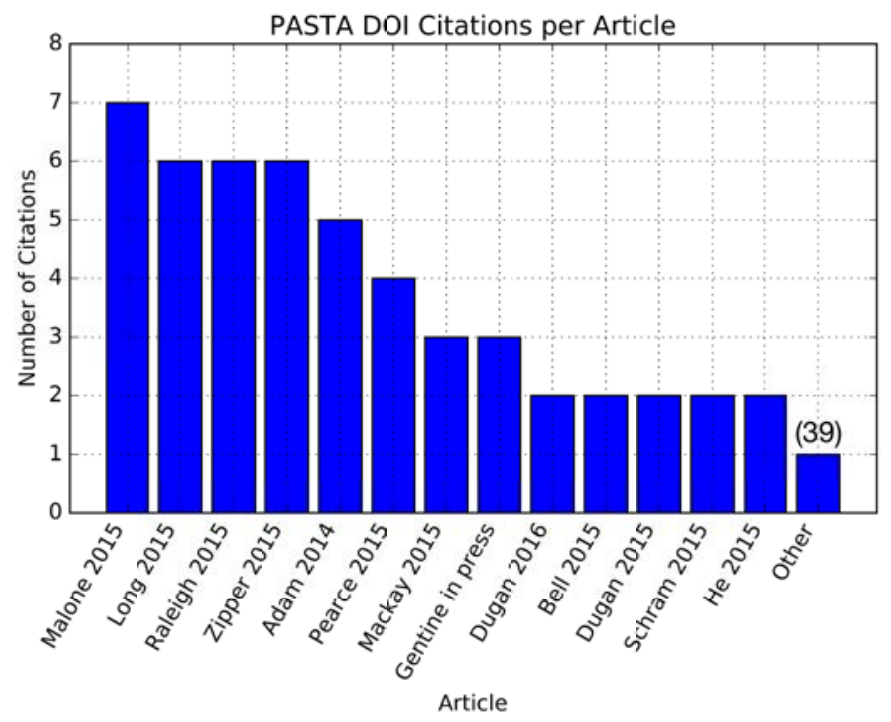

Figure 18: The number of PASTA data packages cited per article. Eighty-nine ( 82 unique) PASTA data packages were identified by DOI as having been cited in an article. Thirteen articles cited more than one data package, while 39 cited only one. 


\section{Conclusions}

We attribute the early adoption of the PASTA framework and the rapid rate of data package uploads to the NIS data repository to the long, inclusive, and open period of preparation that the LTER Network invested in this project. Domain scientists and informatics specialists from the LTER Network and the broader scientific community contributed to the conceptual framework that became the NIS. Software developers worked towards a well-defined set of goals articulated and periodically reviewed by the NIS Advisory Committee (NISAC), whose rotating membership provided essential guidance from both scientific and informatics perspectives. Important recommendations from the NIS included the desirability of building on technology already adopted by the LTER informatics community, such as the Ecological Metadata Language, and the requirement that the NIS integrate seamlessly into existing LTER information management practices as pragmatically as possible. Although PASTA has now met the original goals, we acknowledge that unanticipated requirements and the advent of new informatics technology will always provide the opportunity to expand the capabilities of PASTA to new levels. By continuing to engage data producers, data managers, and data users in ongoing dialogue, we anticipate seamless transitions to future iterations of PASTA. Our recommendation to other developers building data repositories is to engage your community early and often in requirements and design discussions.

As we demonstrate in this paper, the NIS is operating smoothly and has been accepted by the LTER community as the primary outlet for LTER data. Rich metadata has enabled workflow creation through APIs and the assignment of new version numbers for revised data packages combined with the Event Notification service triggers automatic workflows to create updated derived data. Current analysis reveals a bimodal distribution in file size with most files less than $1 \mathrm{MB}$. A few large files (7-50 GB) contribute disproportionally to total volume. This reflects the fact that LTER science combines multi-year and multi-decadal observational studies and experiments with short term experiments designed to understand drivers of long term patterns. Further investigation also shows a bias towards plants and against microbes in data packages that is likely influenced by LTER core areas that stress the former over the latter.

Data re-use is increasing, and the number of first-time and revised data packages are increasing rapidly. Much work remains to be done, however, to achieve the full promise of the NIS. Over 50 proposed data quality checks are yet to be implemented. Recognized best practices (e.g., the Controlled Vocabulary) must be put into effect uniformly across the Network to allow for more detailed analysis of data topics. Data producers need to agree on the optimum approach to lumping timeseries data into data packages consistently. Automated updates of long-term data sets need to be expanded beyond the examples described in this paper. Analysis of data downloads currently is complicated by bots, the result of an open access policy that prohibits collection of data on individuals downloading data. By overcoming these additional challenges, our ability to analyze LTER data and metadata in the NIS will be greatly enhanced.

The potential use of PASTA by other ecological programs and projects requires further examination and planning. By broadening the PASTA user community, we will expand the breadth and depth of data available for ecological synthesis. In the process, we will discover new approaches and requirements that will require improvements to the PASTA framework. Even the flexible design of PASTA may be challenged by the requirements of new communities of data producers and users.

Evaluation of the ultimate goal of the NIS, to accelerate the re-use and synthesis of ecological data, is still beyond our grasp. The upward trends in PASTA data package citation since August 2013, if reflective of future patterns of data re-use, confirm an increasing awareness and dissemination of LTER Network data in keeping with the Networks goal of making long-term ecological data broadly accessible to the research community. This trend, if robust, demonstrates the value of a data repository, such as PASTA, that encourages data citation via DOIs and thus facilitates subsequent data discovery and re-use. Data citation provides a direct link among ideas advanced in an article, the derived data upon which they are based, and the underlying primary data and metadata that exist in a data repository such as PASTA. The fact that the majority of PASTA citations in articles were made by non-LTER researchers offers proof of the dissemination of LTER data beyond the LTER community. Reuse of LTER data demonstrates the importance of open access to data and furthers the mission of the LTER Network to use long-term ecological knowledge to promote the well-being and good management of global ecosystems.

\section{Acknowledgments}

This material is based upon work supported by the National Science Foundation under Cooperative Agreements \#DEB0832652 and \#DEB-0936498. Partial funding for the development of PASTA and the LTER NIS is provided under the American Recovery and Reinvestment Act of 2009 and is administered by the National Science Foundation.

\section{References Cited}

[1] J. R. Gosz, R. B. Waide, J. J. Magnuson, Twenty-eight years of the USLTER program: experience, results, and research questions, in: LongTerm Ecological Research, Springer, 2010, pp. 59-74.

[2] R. B. Waide, M. O. Thomas, Long-term ecological research network, in: Encyclopedia of Sustainability Science and Technology, Springer, 2012, pp. 6216-6240.

[3] M. Servilla, J. Brunt, I. San Gil, D. Costa, PASTA: A network-level architecture design for generating synthetic data products in the LTER Network, http://databits.1ternet.edu/print/121, 2006. [Online; accessed 21-February-2016].

[4] LTER cyberinfrastructure strategic plan, http: //intranet2.1ternet.edu/documents/

lter-cyberinfrastructure-strategic-plan, 2007. [Online; accessed 21-February-2016].

[5] E. H. Fegraus, S. Andelman, M. B. Jones, M. Schildhauer, Maximizing the value of ecological data with structured metadata: an introduction to ecological metadata language (eml) and principles for metadata creation, Bulletin of the Ecological Society of America 86 (2005) 158-168. 
[6] J. A. Mills, C. Teplitsky, B. Arroyo, A. Charmantier, P. H. Becker, T. R. Birkhead, P. Bize, D. T. Blumstein, C. Bonenfant, S. Boutin, et al., Archiving primary data: solutions for long-term studies, Trends in ecology \& evolution 30 (2015) 581-589.

[7] M. C. Whitlock, J. L. Bronstein, E. M. Bruna, A. M. Ellison, C. W. Fox, M. A. McPeek, A. J. Moore, M. A. Noor, M. D. Rausher, L. H. Rieseberg, et al., A balanced data archiving policy for long-term studies, Trends in ecology \& evolution (2015).

[8] J. A. Mills, C. Teplitsky, B. Arroyo, A. Charmantier, P. H. Becker, T. R. Birkhead, P. Bize, D. T. Blumstein, C. Bonenfant, S. Boutin, et al., Solutions for archiving data in long-term studies: A reply to whitlock et al., Trends in ecology \& evolution (2016).

[9] T. Erl, Service-oriented architecture: a field guide to integrating XML and web services, Prentice Hall PTR, 2004.

[10] L. Richardson, S. Ruby, RESTful web services, O’Reilly Media, Inc., 2008.

[11] M. B. Jones, C. Berkley, J. Bojilova, M. Schildhauer, Managing scientific metadata, Internet Computing, IEEE 5 (2001) 59-68.

12] D. Peters, M. Ohman, R. Waide, J. Yao, C. Laney, A. Lugo, S. Collins, C. Driscoll, P. Groffman, J. Grove, A. Knapp, T. Kratz, Long-Term Trends in Ecological Systems: A Basis for Understanding Responses to Global Change, Technical Report 1931, U.S. Department of Agriculture, 2013.

[13] A. K. Knapp, M. D. Smith, Variation among biomes in temporal dynamics of aboveground primary production, Science 291 (2001) 481-484.

[14] E. Muldavin, S. Collins, Core research site web seasonal biomass and seasonal and annual NPP data for the net primary production study at the Sevilleta National Wildlife Refuge, New Mexico (1999), 2011. Long Term Ecological Research Network, doi: 10.6073/pasta/7052c90afd1067a7c4c1b95ea06f9ea406f9ea4.

[15] C. Gries, J. Porter, B. Ruddell, M. Servilla, W. Sheldon, J. Walsh, NIS data workflows best practices 0.1 , https://im.1ternet.edu/sites/ im/NISdataworkflowsbestpractices0.1.pdf, 2016. [Online; accessed 20-February-2016].

[16] B. Leinfelder, J. Tao, D. Costa, M. B. Jones, M. Servilla, M. O’Brien, C. Burt, A metadata-driven approach to loading and querying heterogeneous scientific data, Ecological Informatics 5 (2010) 3-8.

[17] W. K. Michener, S. Allard, A. Budden, R. B. Cook, K. Douglass, M. Frame, S. Kelling, R. Koskela, C. Tenopir, D. A. Vieglais, Participatory design of DataONE - enabling cyberinfrastructure for the biological and environmental sciences, Ecological Informatics 11 (2012) 5-15.

[18] J. Porter, M. OBrien, D. Costa, D. Henshaw, C. Gries, E. Melendez, K. Vanderbilt, J. Downing, J. Laundre, A controlled vocabulary for lter data keywords, in: C. Jones, Matthew B.; Gries (Ed.), Proceedings of the Environmental Information Management Conference 2011, University of California, 2011

\section{Appendix A: List of articles containing PASTA DOI cita- tions}

1. Adam, T.C., Brooks, A.J., Holbrook, S.J., Schmitt, R.J., Washburn, L., Bernardi, G., 2014. How will coral reef fish communities respond to climate-driven disturbances? Insight from landscape-scale perturbations. Oecologia. 176 (1), 285-296. doi:10.1007/s00442-014-3011-x

2. Angelini, C., van der Heide, T., Griffin, J.N., Morton, J.P., Derksen-Hooijberg, M., Lamers, L.P.M., Smolders, A.J.P., Silliman, B.R., 2015. Foundation species' overlap enhances biodiversity and multifunctionality from the patch to landscape scale in southeastern United States salt marshes. Royal Society Proceedings B. 282, 421. doi:10.1098/rspb.2015.0421

3. Barber, G.W., 2015. Ant assemblages of New York State inland pine barrens. Northeastern Naturalist. 22 (3), 551572. doi:10.1656/045.022.0310

4. Bell, T.W., Cavanaugh, K.C., Reed, D.C., Siegel, D.A., 2015. Geographical variability in the controls of giant kelp biomass dynamics. Journal of Biogeography. 42, 20102021. doi:10.1111/jbi.12550

5. Blumstein, M., Thompson, J. R., 2015. Land-use impacts on the quantity and configuration of ecosystem service provisioning in Massachusetts, USA. Journal of Applied Ecology. 52, 1009-1019. doi:10.1111/1365-2664. 12444

6. Castendyk, D., McKnight, D., Welch, K., Niebuhr, S., Jaros, C., 2015. Pressure-driven, shoreline currents in a perennially ice-covered, pro-glacial lake in Antarctica, identified from a $\mathrm{LiCl}$ tracer injected into a pro-glacial stream. Hydrological Processes. 29, 22122231. doi: 10.1002/hyp.10352

7. Castorani, M.C.N., Reed, D.C., Alberto, F., Bell, T.W., Simons, R.D., Cavanaugh, K.C., Siegel, D.A., Raimondi, P.T., In press. Connectivity structures local population dynamics: a long-term empirical test in a large metapopulation system. Ecology. doi : 10.1890/15-0283.1

8. Collins, S.L., Xia, Y., 2015. Long-term dynamics and hotspots of change in a desert grassland plant community. American Naturalist. 185 (2), e30-43. doi:10.1086/ 679315

9. Del Toro, I., Ribbons, R.R., Ellison, A.M., 2015. Antmediated ecosystem functions on a warmer planet: effects on soil movement, decomposition and nutrient cycling. Journal of Animal Ecology. 84 (5), 1233-41. doi:10.1111/1365-2656.12367

10. Dornelas, M., Gotelli, N.J., McGill, B., Shimadzu, H., Moyes, F., Sievers, C., Magurran, A.E., 2014. Assemblage time series reveal biodiversity change but not systematic loss. Science. 344 (6181), 296-299. doi:10. 1126/science. 1248484

11. Dugan, H.A., Arcone, S.A., Obryk, M.K., Doran, P.T., 2016. High-resolution ground-penetrating radar profiles of perennial lake ice in the McMurdo Dry Valleys, Antarctica: Horizon attributes, unconformities, and subbottom penetration. Geophysics. 81, WA13-WA20. doi:10. 1190/geo2015-0159.1

12. Dugan, H.A., Doran, P.T., Wagner, B., Kenig, F., Fritsen, C.H., Arcone, S.A., Kuhn, E., Ostrom, N.E., Warnock, J.P., Murray, A.E., 2015. Stratigraphy of Lake Vida, Antarctica: hydrologic implications of $27 \mathrm{~m}$ of ice. The Cryosphere. 9, 439-450. doi:10.5194/ tc-9-439-2015

13. Eberhardt, A.L., Burdick, D.M., Dionne, M., Vincent, R.E., 2015. Rethinking the freshwater eel: Salt marsh trophic support of the American Eel, Anguilla rostrate. Estuaries and Coasts. 38 (4), 1251-1261. doi:10.1007/ s12237-015-9960-4

14. Foster, M.C., Byrnes, J.E., Reed, D.C., 2014. Effects of five southern California macroalgal diets on consumption, growth, and gonad weight, in the purple sea urchin Strongylocentrotus purpuratus. PeerJ. 3, e719. doi: $10.7717 /$ peerj. .719

15. Gentine, P., Gurin, M., Uriarte, M., McDowell, N.G., Pockman, W.T., In press. An allometry-based model of 
the survival strategies of hydraulic failure and carbon starvation. Ecohydrology. doi : 10.1002/eco. 1654

16. He, Y., D’Odorico, P., De Wekker, S.F., 2015. The role of vegetation-microclimate feedback in promoting shrub encroachment in the northern Chihuahuan desert. Global Change Biology. 21 (6), 2141-2154. doi : 10.1111/gcb. 12856

17. Holbrook. S.J., Schmitt, R.J., Messmer, V., Brooks, A.J., Srinivasan, M., Munday, P.L., et al., 2015. Reef fishes in biodiversity hotspots are at greatest risk from loss of coral species. PLoS ONE. 10 (5), e0124054. doi:10.1371/ journal.pone.0124054

18. Hubbard, A.B., Reidenbach, M.A., 2015. Effects of larval swimming behavior on the dispersal and settlement of the eastern oyster Crassostrea virginica. Marine Ecology Progress Series. 535, 161-176.

19. Kraemer, B.M., Hook, S., Huttula, T., Kotilainen, P., OReilly, C.M., Peltonen, A., et al., 2015. Century-long warming trends in the upper water column of Lake Tanganyika. PLoS ONE. 10 (7), e0132490. doi:10.1371/journal. pone. 0132490

20. Lafferty, K.D., Tinker, M.T., 2014. Sea otters are recolonizing southern California in fits and starts. Ecosphere. 5, art50. doi:10.1890/ES13-00394.1

21. Lenihan, H.S., Hench, J.L., Holbrook, S.J., Schmitt, R.J., Potoski, M., 2015. Hydrodynamics influence coral performance through simultaneous direct and indirect effects. Ecology. 96, 1540-1549. doi:10.1890/14-1115.1

22. Liu, W., Maung-Douglass, K., Strong, D. R., Pennings, S. C., Zhang, Y., 2015. Geographical variation in vegetative growth and sexual reproduction of the invasive Spartina alterniflora in China. Journal of Ecology. doi : 10.1111/ 1365-2745. 12487

23. Long, S.A., Tachiev, G.I., Fennema, R., Cook, A.M., Sukop, M.C., Miralles-Wilhelm, F., 2015. Modeling the impact of restoration efforts on phosphorus loading and transport through Everglades National Park, FL, USA. Science of the Total Environment. 520, 81-95. doi: 10.1016/j.scitotenv. 2015.01.094

24. Lottig, N.R., Wagner, T., Norton Henry, E., Spence Cheruvelil, K., Webster, K.E., Downing, J.A., et al., 2014. Longterm citizen-collected data reveal geographical patterns and temporal trends in lake water clarity. PLoS ONE. 9 (4), e95769. doi:10.1371/journal pone.0095769

25. Mackay, D.S., Roberts, D.E., Ewers, B.E., Sperry, J.S., McDowell, N.G., Pockman, W.T., 2015. Interdependence of chronic hydraulic dysfunction and canopy processes can improve integrated models of tree response to drought. Water Resources Research. 51, 6156D6176. doi : 10.1002/2015WR017244

26. Malone, S.L., Keough, C., Staudhammer, C.L., Ryan, M.G., Parton, W.J., Olivas, P., Oberbauer, S.F., Schedlbauer, J., Starr , G., 2015. Ecosystem resistance in the face of climate change: A case study from the freshwater marshes of the Florida Everglades. Ecosphere. 6:art57. doi:10.1890/ES14-00404.1
27. Marks, L.M., Salinas-Ruiz, P., Reed, D.C., Holbrook, S.J., Culver, C.S., Engle, J.M., et al., 2015. Range expansion of a non-native, invasive macroalga Sargassum horneri (Turner) C. Agardh, 1820 in the eastern Pacific. BioInvasions Records. 4 (4), 243-248. doi:10.3391/bir. 2015.4.4.02

28. Marra, K.R., Elwood Madden, M.E., Soreghan, G.S., Hall, B.L., 2015. BET surface area distributions in polar stream sediments: Implications for silicate weathering in a coldarid environment. Applied Geochemistry. 52, 31-42.

29. McBride, R.A., Fenster, M.S., Seminack, C.T., Richardson, T.M., Sepanik, J.M., Hanley, J.T., et al., 2015. Holocene barrier-island geology and morphodynamics of the Maryland and Virginia open-ocean coasts: Fenwick, Assateague, Chincoteague, Wallops, Cedar, and Parramore Islands. GSA Field Guides. 40, 309-423. doi: 10.1130/2015.0040 (10)

30. McGlathery, K.J., Reidenbach, M.A., D'Odorico, P., Fagherazzi, S., Pace, M.L., Porter, J.H., 2013. Nonlinear dynamics and alternative stable states in shallow coastal systems. Oceanography. 26 (3), 220-231. doi: 10.5670/oceanog. 2013.66

31. McHugh, T.A., Schwartz, E., 2015. Changes in plant community composition and reduced precipitation have limited effects on the structure of soil bacterial and fungal communities present in a semiarid grassland. Plant and Soil. 388 (1), 175-186. doi:10.1007/ s11104-014-2269-4

32. Parker, T.C., Subke, J.A., Wookey, P.A., 2015. Rapid carbon turnover beneath shrub and tree vegetation is associated with low soil carbon stocks at a subarctic treeline. Global Change Biology. 21 (5), 2070-2081. doi: 10.1111/gcb.12793

33. Pearce, A.R., Rastetter, E.B., Kwiatkowski, B.L., Bowden, W.B., Mack, M.C., Jiang, Y., 2015. Recovery of arctic tundra from thermal erosion disturbance is constrained by nutrient accumulation: a modeling analysis. Ecological Applications. 25, 1271-1289. doi : 10.1890/14-1323.1

34. Pelini, S.L., Diamond, S.E., Nichols, L.M., Stuble, K.L., Ellison, A.M., Sanders, N.J., Dunn, R.R., Gotelli, N.J., 2014. Geographic differences in effects of experimental warming on ant species diversity and community composition. Ecosphere. 5, art125. doi:10.1890/ES14-00143

35. Pelini, S.L., Maran, A.M., Chen, A.R., Kaseman, J., Crowther, T.W., 2015. Higher trophic levels overwhelm climate change impacts on terrestrial ecosystem functioning. PLoS ONE. 10 (8), e0136344. doi:10.1371/ journal pone. 0136344

36. Raleigh, M.S., Lundquist, J.D., Clark, M.P., 2015. Exploring the impact of forcing error characteristics on physically based snow simulations within a global sensitivity analysis framework. Hydrology and Earth System Sciences, 19, 3153-3179. doi:10.5194/hess-19-31532015

37. Reed, D.C., Rassweiler, A.R., Miller, R.J., Page, H.M., Holbrook, S.J., 2015. The value of a broad temporal and 
spatial perspective in understanding dynamics of kelp forest ecosystems. Marine and Freshwater Research. doi: 10.1071/MF14158

38. Ryan, M.J., Latella, I.M., Giermakowski, J.T., Snell, H., Poe, S., Pangle, R.E., et al., 2015. Too dry for lizards: short-term rainfall influence on lizard microhabitat use in an experimental rainfall manipulation within a pionjuniper. Functional Ecology. doi : 10.1111/1365-2435. 12595

39. Schram, J. B., et al., 2015. Multi-frequency observations of seawater carbonate chemistry on the central coast of the western Antarctic Peninsula. Polar Research. 34, 25582. doi:10.3402/polar.v34.25582

40. Sepulveda-Jauregui, A., Walter Anthony, K. M., MartinezCruz, K., Greene, S., Thalasso, F., 2015. Methane and carbon dioxide emissions from 40 lakes along a northsouth latitudinal transect in Alaska, Biogeosciences. 12, 31973223. doi : 10.5194/bg-12-3197-2015

41. Sharma, S., et al., 2015.A global database of lake surface temperatures collected by in situ and satellite methods from 19852009. Scientific Data. 2 (150008). doi: 10.1038/sdata. 2015.8

42. Siddig, A.A., Ellison, A.M., Jackson, S., 2015. Calibrating abundance indices with population size estimators of red back salamanders (Plethodon cinereus) in a New England forest. PeerJ. 3, e952. doi:10.7717/peer j.952

43. Thompson, A.R., Adam, T.C., Hultgren, K.M., Thacker, C.E., 2013. Ecology and evolution affect network structure in an intimate marine mutualism. American Naturalist. 182 (2), 58-72. doi : 10.1086/670803

44. Timko, S.A., Romera-Castillo, C., Jaff, R., Cooper, W.J., 2014. Photo-reactivity of natural dissolved organic matter from fresh to marine waters in the Florida Everglades, USA. Environmental Science: Processes \& Impacts. 16 (4), 866-878. doi:10.1039/c3em00591g

45. Torres-Moye, G., Escofet, A., 2014. Land-sea interactions in Punta China (Baja California, Mxico): Addressing anthropic and natural disturbances in a retrospective context. Journal of Environmental Protection. 5, 1520-1530. doi: 10.4236/jep. 2014.516144

46. Walter Anthony, K.M., Zimov, S.A., Grosse, G., Jones, M.C., Anthony, P.M., Chapin III, F.S., et al., 2014. A shift of thermokarst lakes from carbon sources to sinks during the Holocene epoch. Nature. 511, 452-456. doi: 10.1038/nature13560

47. Wiberg, P.L., Carr, J.A., Safak, I., Anutaliya, A., 2015. Quantifying the distribution and influence of non-uniform bed properties in shallow coastal bays. Limnology and Oceanography: Methods. doi:10.1002/Iom3.10063

48. Wright, K.W., Vanderbilt, K.L., Inouyeb, D.W., Bertelsen, C.D., Crimmins, T.M., 2015. Turnover and reliability of flower communities in extreme environments: Insights from long-term phenology data sets. Journal of Arid Environments. 115, 27-34.

49. Yang, N., Welch, K.A., Mohajerin, T.J., Telfeyan, K., Chevis, D.A., Grimm, D.A., et al., 2015. Comparison of arsenic and molybdenum geochemistry in meromictic lakes of the McMurdo Dry Valleys, Antarctica: Implications for oxyanion-forming trace element behavior in permanently stratified lakes. Chemical Geology. 404, 110125.

50. Yue, X., Unger, N., 2015. The Yale Interactive terrestrial Biosphere model version 1.0: description, evaluation and implementation into NASA GISS ModelE2. Geoscientific Model Development. 8, 2399-2417. doi : 10.5194/ gmd-8-2399-2015

51. Yue, X., Unger, N., Keenan, T.F., Zhang, X., Vogel, C.S., 2015. Probing the past 30-year phenology trend of US deciduous forests. Biogeosciences. 12, 4693-4709. doi: 10.5194/bg-12-4693-2015

52. Zipper, S.C., Soylu, M.E., Booth, E.G., Loheide II, S.P., 2015. Untangling the effects of shallow groundwater and soil texture as drivers of subfield-scale yield variability, Water Resources Research. 51, 6338-6358. doi:10. 1002/2015WR017522 